\title{
An Analytical Survey of Trace Heavy Elements in Insecticides
}

\author{
Maha Abdallah Alnuwaiser (D) \\ Department of Chemistry, College of Science, Princess Nourah bint Abdulrahman University, P.O. Box 28445, \\ Riyadh 11437, Saudi Arabia \\ Correspondence should be addressed to Maha Abdallah Alnuwaiser; maalnoussier@pnu.edu.sa
}

Received 17 December 2018; Revised 10 April 2019; Accepted 22 April 2019; Published 29 May 2019

Academic Editor: Eladia M. Pena-Mendez

Copyright (C) 2019 Maha Abdallah Alnuwaiser. This is an open access article distributed under the Creative Commons Attribution License, which permits unrestricted use, distribution, and reproduction in any medium, provided the original work is properly cited.

\begin{abstract}
There are many types of insecticides traded in the local and international markets, which vary depending on the type of target insect (e.g., whether crawling or flying). This paper aimed to assess the concentration of trace elements present in the various pesticide formulations (solid, liquid, and gaseous). This study was conducted in two groups: the first group was comprised of zinc, copper, iron, chromium, phosphorus, selenium, and cobalt; the second group included four heavy toxic elements (arsenic, thallium, lead, and mercury). These elements were analyzed by inductively coupled plasma/optical emission spectrometry (ICP-OES).
\end{abstract}

\section{Introduction}

With the growth of the world population, food production will need to increase by more than $60 \%$, assisted by the safe and effective use of pesticides. Pesticides have an important role in helping to eliminate insects that destroy crops or cause epidemics diseases [1-5].

The increase in the use of pesticides often results in many adverse impacts, especially on the agricultural environment $[6,7]$. For this reason, various analytical techniques are used to test pesticides, including chromatographic methods $[8,9]$. Pesticides are widely used [10] in agriculture, medicine, and industry and have the potential to change the ecosystem [11]. Pesticides contain active ingredients and are used to ensure that high agricultural yield and quality can be achieved, but can cause environmental pollution if used incorrectly [12]. Organophosphorus pesticides (e.g., tebufenozide, chromafenozide, methoxyfenozide, and acetonitrile) [13] target those pests affecting fruit and vegetable crops, such as apples, grapes, cucumbers, cabbage, tomatoes, and spinach [14].

Some pesticides have large effects on mental and reproductive health and the developmental neural degenerative diseases among pregnant women and children $[1,4,9]$. If the percentage of pesticide toxicity dose increases, it leads to asthma and anaphylaxis in the human nervous system $[9,15]$.

Pesticide alternatives often reduces the need for pesticides, including systemic insecticides, which are highly effective in the elimination of crop pests, using biological soil, pest-resistant tools, and fatty acid salts (potassium salts) [16]. Pyrethroids are used as an alternative to highly toxic pesticides and are inexpensive $[17,18]$. Neonicotinoids, alternatives to pesticides, are widely used in agriculture and are highly water-soluble [19]. Many pesticides and heavy metals are durable and nonbiodegradable and can accumulate along biological chains (soil, plants, food, and seawater) [20]. Therefore, the presence of large amounts of pesticides and heavy metals in the environment represents a risk to human health and the environment. For this reason, accurate monitoring of these concentrations plays an important role [21]. The literature cites many methods for heavy metal determination in soils, phosphorus rocks, seawater, plants, biologic materials, steel, and cast iron, including inductive coupled plasma-mass spectrometry [22], inductive coupled plasma atomic emission spectrometry [23], atomic absorption spectrometry with flame or electrothermal atomization [24], electrochemically with ultramicroelectrodes [25], and anodic stripping voltammetry [26].

For these reasons, we chose to determine the concentrations of heavy metals and pesticides in insecticides. This work investigates trace (zinc, copper, iron, chromium, phosphorus, selenium, and cobalt) and heavy metal (arsenic, thallium, lead, and mercury) pollution of pesticides. The trace and heavy metals were analyzed using inductively coupled plasma/optical emission spectrometry (ICP-OES). 
TABLE 1: The percentage (ppb) of elements under study in liquid insecticides samples.

\begin{tabular}{|c|c|c|c|c|c|c|c|}
\hline \multirow{2}{*}{\multicolumn{2}{|c|}{ Elements }} & \multicolumn{6}{|c|}{ Liquid pesticides samples } \\
\hline & & \multirow{2}{*}{$\begin{array}{c}\text { Cyper Safe } \\
968\end{array}$} & \multirow{2}{*}{$\frac{\text { CyperCel }}{2389}$} & \multirow{2}{*}{$\frac{\text { Sniper }}{506}$} & \multirow{2}{*}{$\frac{\text { Scope }}{527}$} & \multirow{2}{*}{$\frac{\text { Brodor }}{10}$} & \multirow{2}{*}{$\frac{\text { CLASH }}{1078}$} \\
\hline \multirow{7}{*}{ Basic elements } & Zinc & & & & & & \\
\hline & Copper & 464 & 669 & 423 & 539 & 0 & 0 \\
\hline & Iron & 1202 & 3117 & 46190 & 5892 & 664 & 3676 \\
\hline & Chromium & 10 & 373 & 746 & 437 & 16 & 73 \\
\hline & Phosphorous & 0 & 377 & 0 & 0 & 80 & 842 \\
\hline & Selenium & 0 & 0 & 0 & 0 & 0 & 0 \\
\hline & Cobalt & 6 & 18 & 275 & 23 & 0 & 39 \\
\hline \multirow{4}{*}{ Toxic elements } & Arsenic & 0 & 0 & 0 & 0 & 0 & 0 \\
\hline & Thallium & 0 & 0 & 0 & 0 & 92 & 0 \\
\hline & Lead & 119 & 807 & 88 & 39 & 186 & 1316 \\
\hline & Mercury & 0 & 0 & 0 & 0 & 0 & 0 \\
\hline
\end{tabular}

\section{Materials and Methods}

2.1. The Samples and Their Sources. In October 2018, sixteen commonly available pesticides samples were collected from the local markets in Riyadh, Saudi Arabia. These samples cover the two types of exterminating insect (crawls and flying) and were classified into three major groups depending on the physical statement (solid, liquid, and gaseous). The first group consists of six solid pesticide samples [Acefed powder (mithomail), Probalt wettable powder (aimida klobrid), Nur cam 5 de-powder cypermethrin), over 50000 de me a powder (Malathion), and Cockroach powder (Deltamethrin)]. The second group included six liquid pesticide samples [Cyper Safe aqueous, a microscopic effective cypermethrin; Cyber art, a 100 Torrent AC emulsification liquid with active substance cypermethrin; Sniper-Center, a commentator fluid with active substance fipronil; Scope $60 \mathrm{w}$, an odorless liquid with active substance Asaybrmthrin; Brodeur 20\%, a DSL liquid soluble in water with active ingredient aimida klobrid; and Rajesh 25, an AC liquid EC with active ingredient Deltamethrin]. The third group has four gas pesticide samples (Pif Paf for all bugs, with active substances imiprothrin and transfluthrin; Pigeon flies and mosquitoes with the active substances phenothrin and permethrin; Pigeon for cockroaches and ants with active substances pyrethroid and cypermethrin and imiprothrin; and Raid for all insects, with active substance imiprothrin and cyfluthrin).

2.2. Preparation of Samples. In the case of solid samples, 1.0 $\mathrm{g}$ was dissolved in $10 \mathrm{~mL}$ distilled water and filtered. For the liquid samples, $1.0 \mathrm{~g}$ of each sample was mixed with distilled water to a final volume of $10 \mathrm{~mL}$. For the gaseous samples, the aerosols were collected from the packets by spraying in the separation funnel, and equal amounts of distilled water were added. The mixtures were shaken well and allowed to separate overnight. The aqueous layer was then isolated from the funnel and filtered.

2.2.1. Precautions. No heating or acid digestion was performed due to the volatility of the samples. To accurately determine the dissolved elements, the samples were filtered using a $0.45-\mu \mathrm{m}$ membrane.

2.3. Instruments. Measurements of the trace and heavy elements were performed using a Perkin Elmer ICP-OES Optima 7300 DV Spectrometer.

Operating Conditions: plasma gas flow, $15 \mathrm{~L} / \mathrm{min}$; auxiliary gas flow, $0.2 \mathrm{~L} / \mathrm{min}$; nebulizer gas flow, $0.6 \mathrm{~L} / \mathrm{min}$; RF power, 1450 watts; plasma view axial read parameters, $2.0 \mathrm{~min}, 5.0$ max; peristaltic pump flow rate, $1.5 \mathrm{~mL} / \mathrm{min}$; number of replicates, 3 ; resolution, normal; aqueous torch assembly.

Wavelengths used for the elements: $\operatorname{arsenic}($ As), 193.696; chromium $(\mathrm{Cr}), 205.560$; cobalt $(\mathrm{Co}), 228.616$; $\operatorname{copper}(\mathrm{Cu})$, 324.752; iron $(\mathrm{Fe}), 239.562$; lead $(\mathrm{Pb}), 220.353$; mercury $(\mathrm{Hg})$, 253.652; phosphorous(P), 213.617; selenium(Se), 203.985; thallium(Tl), 276.787; Zinc (Zn), 213.857.

2.4. Data Analysis and Calculations. The measurement units for the assessed samples (solid, liquid, and aerosol) are microgram per liter (ug/L) or Parts Per Billion (ppb). For trace elements with zero ppb, these were considered as "nondetectable", meaning that the analyte concentration/intensity was negative or that the analyte concentration is below the method's detection limit.

\section{Results and Discussion}

Some of the trace (zinc, copper, iron, chromium, phosphorus, selenium, and cobalt) and heavy (arsenic, thallium, lead, and mercury) elements in solid, liquid, and gaseous pesticides species were determined by spectrometry. This study focused on the three insecticide categories consisting of six liquid, six solid, and four gaseous samples. Among the liquid insecticides samples, selenium, arsenic, and mercury were not detected (Table 1 and Figure 1). The concentrations of the other elements $(\mathrm{Zn}, \mathrm{Cu}, \mathrm{Fe}, \mathrm{Cr}, \mathrm{P}, \mathrm{Co}, \mathrm{Tl}$, and $\mathrm{Pb}$ ) varied. Among the solid pesticide samples, zinc, phosphorus, selenium, arsenic, thallium, and mercury were absent (Table 2 and Figure 2). On the other hand, it was found that most of the samples of gaseous pesticides are free of all studied elements, 


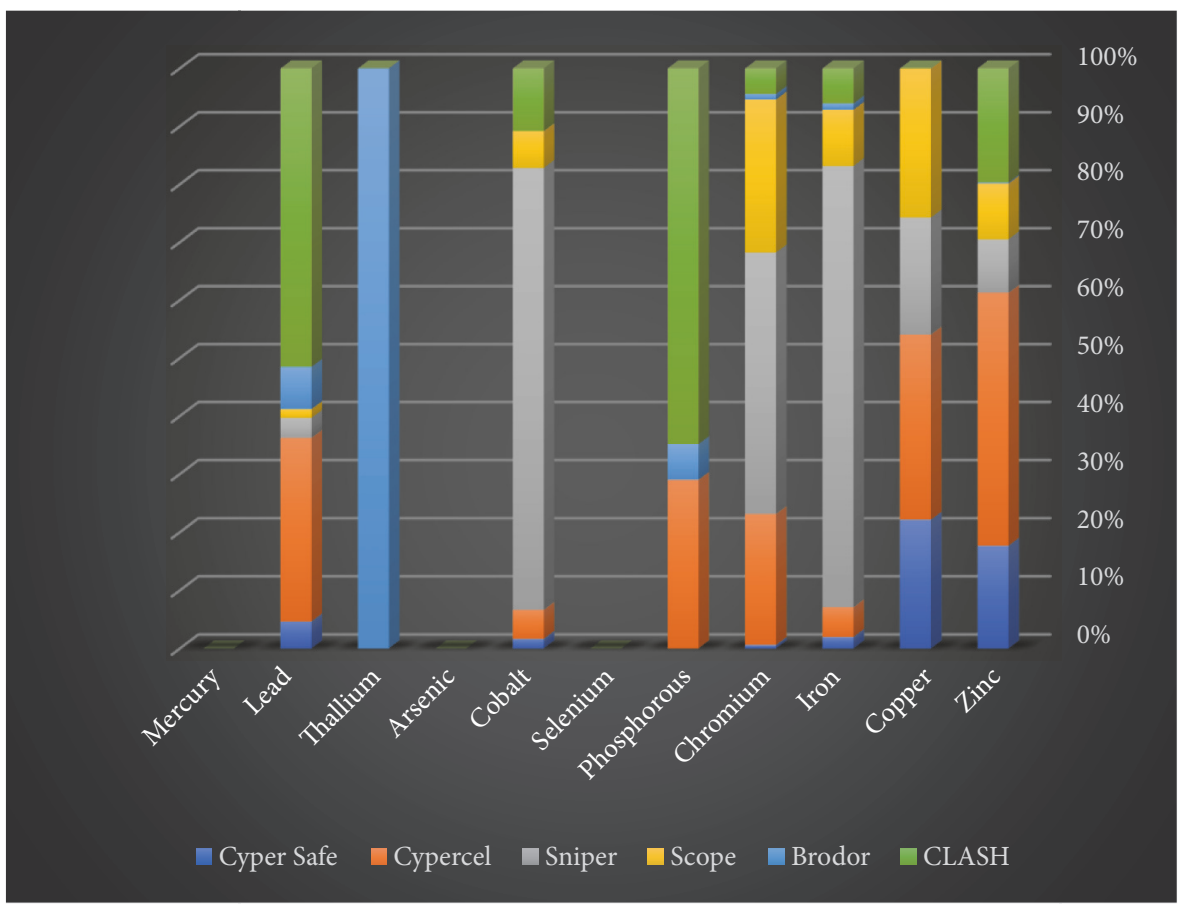

FIGURE 1: Proportions of the studied elements in the liquid insecticides samples.

TABLE 2: The percentage (ppb) elements in the solid insecticides samples.

\begin{tabular}{|c|c|c|c|c|c|c|c|}
\hline \multirow{2}{*}{\multicolumn{2}{|c|}{ Elements }} & \multicolumn{6}{|c|}{ Solid pesticides samples } \\
\hline & & Acefed & Lanid & Probalt & Nourcam & Madar & Pif Paf \\
\hline \multirow{7}{*}{ Basic elements } & Zinc & 0 & 0 & 0 & 0 & 10 & 0 \\
\hline & Copper & 19 & 128 & 179 & 0 & 66 & 110 \\
\hline & Iron & 4298 & 1675 & 3655 & 13 & 29 & 102 \\
\hline & Chromium & 48 & 60 & 85 & 0 & 16 & 0 \\
\hline & Phosphorous & 0 & 0 & 0 & 0 & 0 & 0 \\
\hline & Selenium & 0 & 0 & 0 & 0 & 0 & 0 \\
\hline & Cobalt & 4 & 1 & 25 & 1 & 10 & 5 \\
\hline \multirow{4}{*}{ Toxic elements } & Arsenic & 0 & 0 & 0 & 0 & 0 & 0 \\
\hline & Thallium & 0 & 0 & 0 & 0 & 0 & 0 \\
\hline & Lead & 121 & 98 & 46 & 0 & 0 & 0 \\
\hline & Mercury & 0 & 0 & 0 & 0 & 0 & 0 \\
\hline
\end{tabular}

and some of them contain only two to four elements (Table 3 and Figure 3).

The zinc, copper, iron, chromium, phosphorus, cobalt, thallium, and lead elements were detected in all liquid insecticide samples (Table 1). Among the liquid insecticides, the zinc concentration was highest in CyperCel (2389 ppb) and Clash (1078ppb) and lowest in Brodor (10ppb). Copper was detected in four of the liquid pesticide samples [Cyper Safe (464 ppb), CyperCel (669 ppb), Sniper (423 ppb), and Scope (539 ppb)]. The iron content was high in the Sniper pesticide $(46,190 \mathrm{ppb})$ in case of the six types of liquid insecticides. The percentage of chromium element was increased in case of the three insecticide samples (Sniper (746 ppb), Scope (437 ppb), and CyperCel (373 ppb)) but it has the lowest concentration in case of the two pesticide samples (Cyper Safe
(10 ppb) and Brodor (16 ppb)), respectively. Among the liquid insecticide samples, the phosphorus concentration was high in Clash (842 ppb), but was not detected in Cyper Safe, Sniper, and Scope. The cobalt concentrations were as follows: Sniper (275 ppb), Clash (39 ppb), Scope (23 ppb), and CyperCel (18 ppb). Thallium was present only in the liquid Brodor sample (92ppb). Among the liquid insecticides, lead was detected in (from the highest to the lowest) Clash (1316 ppb), CyperCel (807 ppb), Brodor (186 ppb), Cyper Safe (119 ppb), Sniper (88 $\mathrm{ppb})$, and Scope (39 ppb).

Zinc, copper, iron, chromium, cobalt, and lead elements were detected in all of the solid insecticide samples (Table 2). Among the solid insecticide samples, the lowest detectable concentration of zinc was found in Madar (10 ppb). Zinc was absent from the solid samples of Acefed, Lanid, Probalt, 


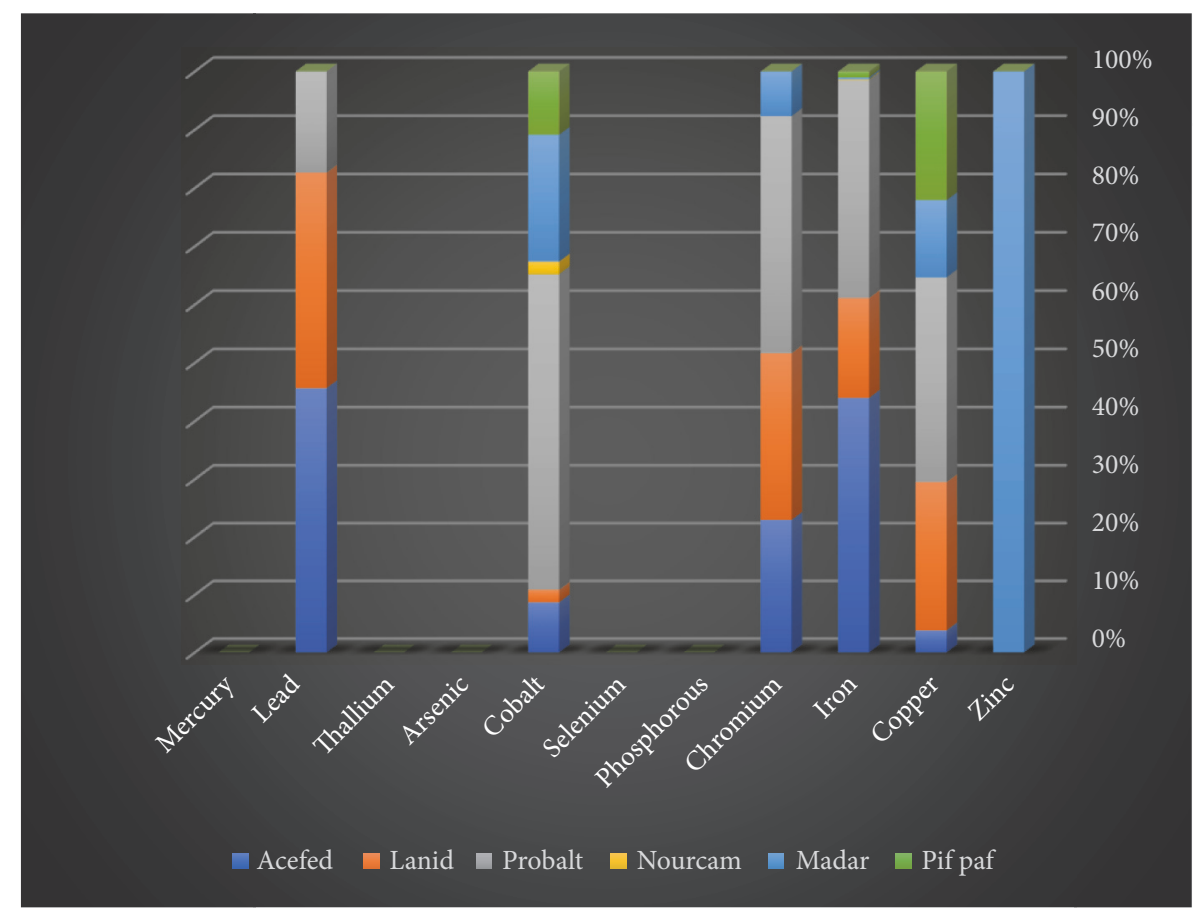

Figure 2: Proportions of the studied elements in solid insecticides samples.

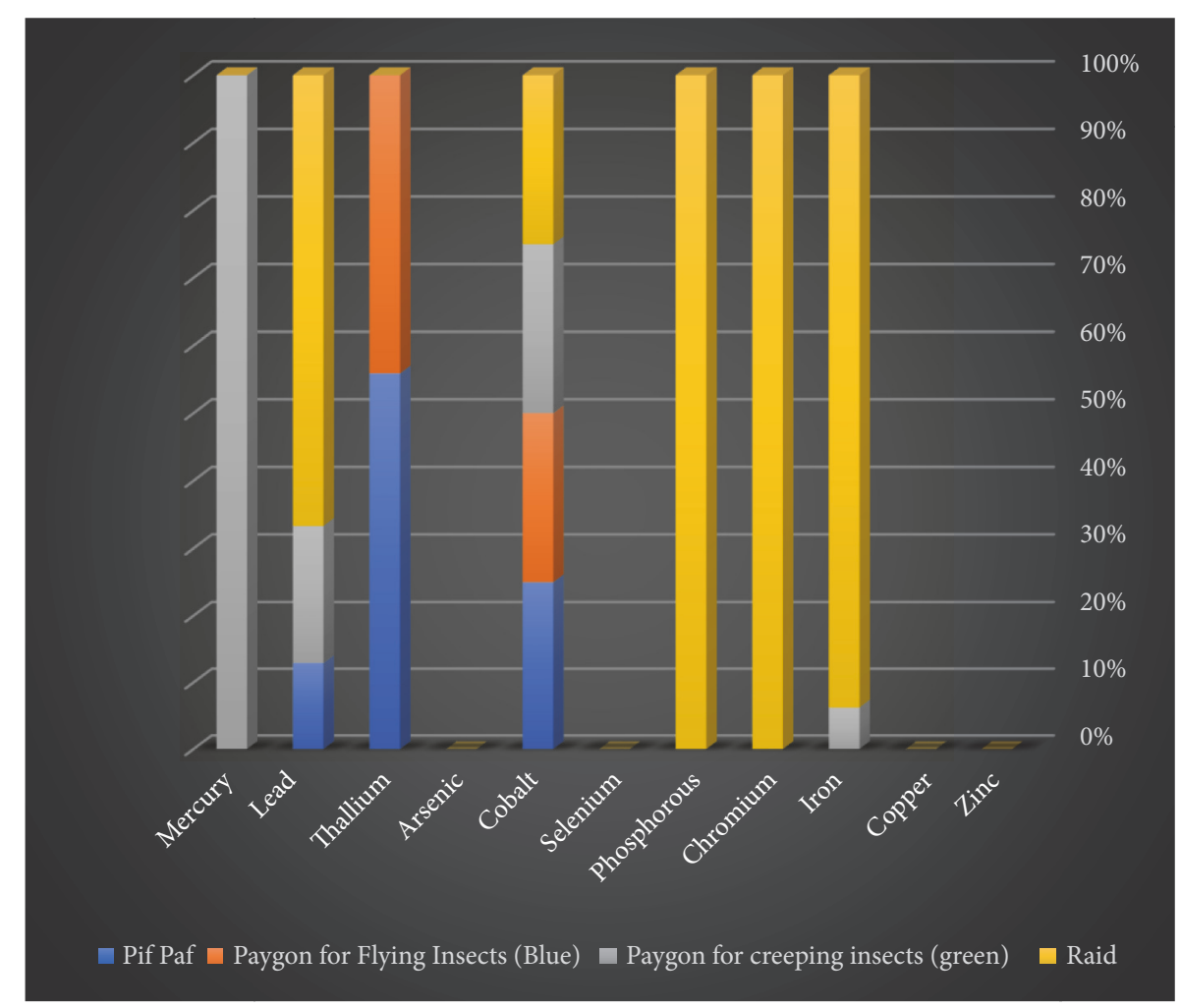

FIgURE 3: Proportions of the studied elements in the gaseous insecticides samples. 
TABle 3: The percentage (ppb) elements in the gaseous insecticides samples.

\begin{tabular}{|c|c|c|c|c|c|}
\hline \multirow{2}{*}{\multicolumn{2}{|c|}{ Elements }} & \multicolumn{4}{|c|}{ Gaseous pesticides samples } \\
\hline & & Pif Paf & Paygon for Flying Insects (Blue) & Paygon for creeping insects (green) & Raid \\
\hline \multirow{7}{*}{ Basic elements } & Zinc & 0 & 0 & 52 & 0 \\
\hline & Copper & 0 & 0 & 0 & 0 \\
\hline & Iron & 0 & 0 & 10 & 150 \\
\hline & Chromium & 0 & 0 & 0 & 33 \\
\hline & Phosphorous & 0 & 0 & 0 & 20 \\
\hline & Selenium & 0 & 0 & 0 & 0 \\
\hline & Cobalt & 1 & 1 & 1 & 1 \\
\hline \multirow{4}{*}{ Toxic elements } & Arsenic & 0 & 0 & 0 & 0 \\
\hline & Thallium & 19 & 15 & 0 & 0 \\
\hline & Lead & 12 & 0 & 19 & 62 \\
\hline & Mercury & 0 & 0 & 0 & 0 \\
\hline
\end{tabular}

Nourcam, and Pif Paf. The percentages of copper element in case of the three solid pesticide Lanid, Probalt, and Pif Paf samples are $128 \mathrm{ppb}, 179 \mathrm{ppb}$, and $110 \mathrm{ppb}$, respectively. The highest concentration value of copper element is represented in case of the Probalt pesticide and decreases in case of the Acefed (19 ppb) and Madar (66 ppb) but has a nil percentage in case of Nourcam sample. The highest percentage of iron element was observed in case of the Acefed pesticide (4298 $\mathrm{ppb}$ ) compared with all the elements in this study which was applied on the six types of solid insecticides. The percentages of the chromium element for the three insecticide samples of Probalt, Lanid, and Acefed are $85 \mathrm{ppb}, 60 \mathrm{ppb}$, and 60 $\mathrm{ppb}$, respectively, but in case of Madar pesticide sample, the concentration is $16 \mathrm{ppb}$. Cobalt was detected in Acefed (4 ppb), Lanid (1 ppb), Probalt (25 ppb), Nourcam (1 ppb), Madar (10ppb), and Pif Paf (5 ppb), respectively. In the solid insecticides, lead was detected in (from highest to the lowest) Acefed (121 ppb), Lanid (98 ppb), and Probalt (46 ppb).

$\mathrm{Zn}, \mathrm{Fe}, \mathrm{Cr}, \mathrm{P}, \mathrm{Co}, \mathrm{Tl}$, and $\mathrm{Pb}$ were detected in the four gaseous pesticide samples (Table 3 ). Zinc element was found only in one insecticide sample (Paygon for creeping insects, green, $52 \mathrm{ppb}$ ). The iron content was highest in the Raid insecticide (150 ppb) and lowest in Paygon for creeping insects (green). Both chromium and phosphorus were detected only in the Raid insecticide (33 and $20 \mathrm{ppb}$, respectively). Thallium was detected in two samples [Pif Paf (19 ppb) and Paygon for flying insects (blue)]. The lead concentration was highest in the case of Raid (62 ppb), but was not detected for Paygon for flying insects (blue).

The impacts of the active substance in different insecticides and in different kinds of insecticide (liquid-solid, solidgas, solid-liquid) are listed in Table 4.

(i) Active Substances in the Similar Insecticide Types. Among the liquid insecticide samples, the zinc concentration was highest in CyperCel (2389 ppb) and Cyper Safe (968 ppb), lowest in Paygon for creeping insects (green) (52 ppb), and absent from the solid insecticides. The percentages of copper element are $464 \mathrm{ppb}$ and $669 \mathrm{ppb}$ in case of the two liquid pesticide samples Cyper Safe and CyperCel, respectively. The concentration of copper became lower in case of the solid samples Acefed (19 ppb) and Lanid (128 ppb), respectively, but the copper ratio is nil for the gaseous samples. The concentration of iron element is increased in both liquid and solid insecticide samples, while it has a nil or $10 \mathrm{ppb}$ concentration in the Pif Paf and Paygon gaseous pesticide samples, respectively. The percentage of chromium element is detected in case of the liquid and solid pesticide samples with different ratios, but it has a nil ratio in gaseous samples. The concentration of phosphorus ratio is nil in case of solid and gaseous pesticide samples, while it was presented in one of the liquid insecticide samples, CyperCel (377 ppb). Selenium and mercury elements were detected in none of the three pesticide types (liquid, solid, and gas). Cobalt was present in the three samples at 1-18 ppb. Thallium was detected in one of the gaseous samples (Pif Paf, $19 \mathrm{ppb}$ ). Lead was present in the three cases of pesticide samples with different ratios. It has a higher concentration in case of the liquid samples than in solid insecticide samples, while it was present in gaseous samples with lower ratio.

(ii) Active Substances in the Different Insecticide Types. The highest percentage of zinc element is presented in case of Clash (1078 ppb) liquid insecticide in comparison with Pif Paf solid insecticide sample. The highest ratio of copper element is present in case of Probalt (179 ppb) solid insecticide sample in comparison with a liquid sample (Brodor, nil percentage). The iron ratio was higher in the solid sample (3655 ppb, Probalt) than in the liquid sample (664 ppb, Brodor) and, paradoxically, the ratio of iron in liquid Clash was higher than in Pif Paf solid (3676 ppb vs. $102 \mathrm{ppb}$ ). The chromium ratio has a $85 \mathrm{ppb}$ in case of Probalt solid insecticide sample. This ratio is higher than liquid Brodor insecticide sample (16 ppb). Paradoxically, it was found that the ratio of chromium in case of liquid Clash sample (73 ppb) is higher than solid Pif Paf sample (nil). The phosphorus element ratio is only present in case of Brodor and Clash liquid insecticide samples as 80 ppb and $842 \mathrm{ppb}$, respectively. The cobalt element is present in case of the Clash liquid sample (39 ppb) with moderate ratio but it has a lower ratio in case of the solid and gaseous samples. The percentages of selenium, arsenic, and mercury elements are nil in case of the three (liquid-solid, solid-gas, 


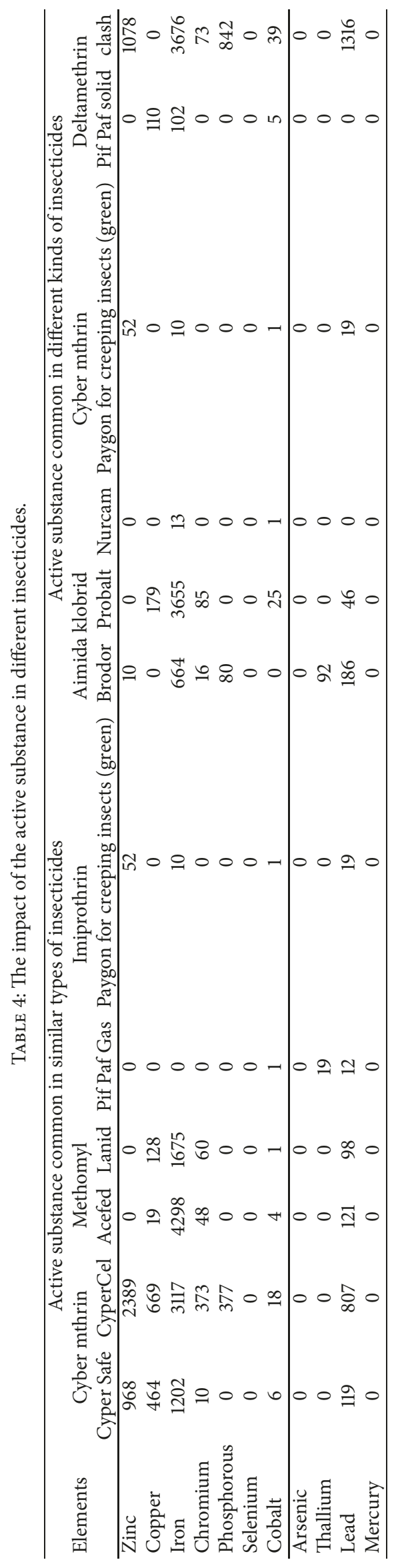




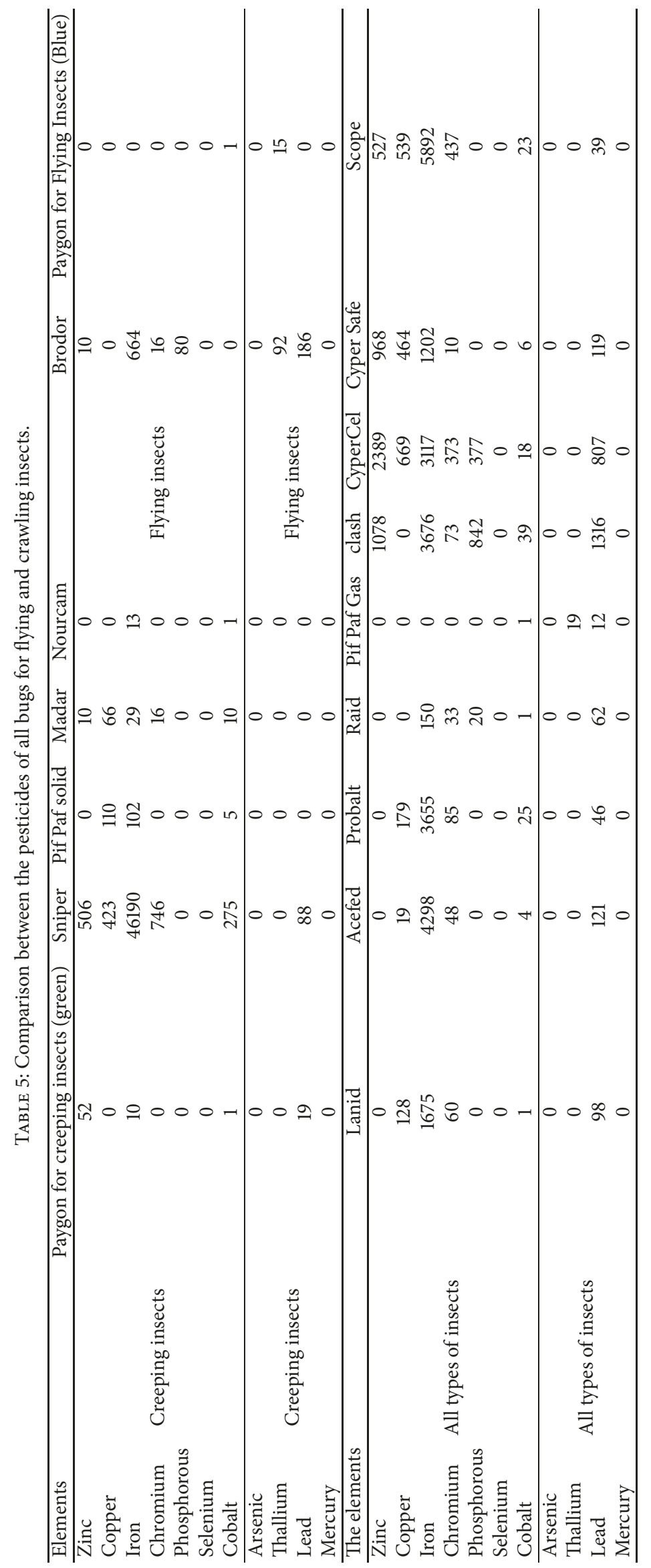


solid-liquid) samples. The thallium ratio is only found in one liquid sample (Brodor, moderate ratio, $92 \mathrm{ppb}$ ). Lead element was present in the three cases with different ratios. It has a higher concentration in case of the Clash liquid sample (1316 $\mathrm{ppb}$ ) rather than the solid and gaseous insecticide samples.

The studied insecticides were divided into three groups: insect insecticides, insecticides, and insecticides for all types of insects. For the tested creeping insect insecticides, Sniper had the highest concentration of elements (Table 5). For flying insect insecticides, the liquid Brodor insecticide contained a higher concentration of elements than the biodegradable insecticide. Also, we found that the liquid insecticides contained higher concentrations of elements than the solid and gaseous pesticides. When comparing insecticides from the same case and product, it can be concluded that the Paygon for insects is more likely to occur in the appearance and concentration of elements. When comparing the different physical formulations, the Pif Paf solid concentrates contained copper and iron elements rather than the Pif Paf gas vaporizer samples. We tested the effect of the odor ratio on pesticides using two types of liquid and cruciferous insecticides (of the same composition and active substance). Compared to CyperCel odor, the element concentrations were lower in the Cybersif syrup insecticide.

\section{Data Availability}

The data used to support the findings of this study are available from the author upon request.

\section{Conflicts of Interest}

The author declares no conflicts of interest.

\section{References}

[1] V. Muinic and D. Želježić, "Non-target toxicity of novel insecticides," Archives of Industrial Hygiene and Toxicology, vol. 69, no. 2, pp. 86-102, 2018.

[2] M. Chagnon, D. Kreutzweiser, E. A. D. Mitchell, C. A. Morrissey, D. A. Noome, and J. P. Van Der Sluijs, "Risks of largescale use of systemic insecticides to ecosystem functioning and services," Environmental Science and Pollution Research, vol. 22, no. 1, pp. 119-134, 2015.

[3] C. W. Holyoke, D. Cordova, W. Zhang et al., "Mesoionic insecticides: a novel class of insecticides that modulate nicotinic acetylcholine receptors," Pest Management Science, vol. 73, no. 4, pp. 796-806, 2017.

[4] A. Malik, E. Grohmann, and R. Akhtar, Environmental Deterioration and Human Health: Natural And Anthropogenic Determinants, Springer, Dordrecht, Netherlands, 2014.

[5] M. D. Green, M. Mayxay, R. Beach et al., "Evaluation of a rapid colorimetric field test to assess the effective life of long-lasting insecticide-treated mosquito nets in the Lao PDR," Malaria Journal, vol. 12, no. 1, p. 57, 2013.

[6] V. V. Oberemok, K. V. Laikova, Y. I. Gninenko, A. S. Zaitsev, P. M. Nyadar, and T. A. Adeyemi, "A short history of insecticides," Journal of Plant Protection Research, vol. 55, no. 3, pp. 221-226, 2015.
[7] J. Fischer, A. Hájková, M. Pereira, M. Kř̌č̌ek, V. Vyskočil, and J. Barek, "Investigation of voltammetric behaviour of insecticide chlorpyrifos on a mercury meniscus modified silver solid amalgam electrode," Electrochimica Acta, vol. 216, pp. 510-516, 2016.

[8] R. Šelešovská, L. Janíková-Bandžuchová, M. Kadubcová, and M. Štěpánková, "Voltammetric behavior of the insecticide pymetrozine on a mercury meniscus modified silver solid amalgam electrode," Analytical Letters, vol. 49, no. 1, pp. 4-18, 2016.

[9] K. Rangasamy, A. Murugan, N. Devarajan et al., "Pesticide degrading natural multidrug resistance bacterial flora," Microbial Pathogenesis, vol. 114, pp. 304-310, 2018.

[10] K. Yin, Y. Deng, C. Liu et al., "Kinetics, pathways and toxicity evaluation of neonicotinoid insecticides degradation via UV/chlorine process," Chemical Engineering Journal, vol. 346, no. 15, pp. 298-306, 2018.

[11] M. Suganthi and K. P. Elango, "Binding of organophosphate insecticides with serum albumin: multispectroscopic and molecular modelling investigations," Physics and Chemistry of Liquids, vol. 55, no. 2, pp. 165-178, 2017.

[12] J. Fenoll, I. Garrido, P. Hellín, P. Flores, and S. Navarro, "Photodegradation of neonicotinoid insecticides in water by semiconductor oxides," Environmental Science and Pollution Research, vol. 22, no. 19, pp. 15055-15066, 2015.

[13] M. E. Khalifa, I. M. M. Kenawy, Y. G. Abou El-Reash, and A. B. Abdallah, "Extractive separation of Profenofos as an organophosphorous insecticide from wastewater and plant samples using molecular imprinted cellulose," Journal of Environmental Chemical Engineering, vol. 5, no. 4, pp. 3447-3454, 2017.

[14] X. Liu, J. Xu, F. Dong, Y. Li, W. Song, and Y. Zheng, "Residue analysis of four diacylhydrazine insecticides in fruits and vegetables by Quick, Easy, Cheap, Effective, Rugged, and Safe (QuEChERS) method using ultra-performance liquid chromatography coupled to tandem mass spectrometry," Analytical and Bioanalytical Chemistry, vol. 401, no. 3, pp. 1051-1058, 2011.

[15] K. Vikrant, D. C. W. Tsang, N. Raza, B. S. Giri, D. Kukkar, and K.-H. Kim, "Potential utility of metal-organic frameworkbased platform for sensing pesticides," ACS Applied Materials \& Interfaces, vol. 10, no. 10, pp. 8797-8817, 2018.

[16] L. Furlan, A. Pozzebon, C. Duso et al., "An update of the Worldwide Integrated Assessment (WIA) on systemic insecticides. Part 3: alternatives to systemic insecticides," Environmental Science and Pollution Research, pp. 1-23, 2018.

[17] P. N. Tran, S. H. J. Brown, M. Rug, M. C. Ridgway, T. W. Mitchell, and A. G. Maier, "Changes in lipid composition during sexual development of the malaria parasite Plasmodium falciparum," Malaria Journal, vol. 15, p. 146, 2016.

[18] A. Gajendiran and J. Abraham, "An overview of pyrethroid insecticides," Frontiers in Biology, vol. 13, no. 2, pp. 79-90, 2018.

[19] M. Raby, M. Nowierski, D. Perlov et al., "Acute toxicity of 6 neonicotinoid insecticides to freshwater invertebrates," Environmental Toxicology and Chemistry, vol. 37, no. 5, pp. 14301445, 2018.

[20] A. W. al. Shawi and R. Dahl, "The determination of cadmium and six other heavy metals in nitrate/phosphate fertilizer solution by ion chromatography," Analytica Chimica Acta, vol. 391, no. 1, pp. 35-42, 1999.

[21] M. C. Pablos Espada, A. Garrido Frenich, J. L. Martinez Vidal, and P. Parrilla, "Comparative study using ecd, npd, and ms/ms 
chromatographic techniques in the determination of pesticides in wetland waters," Analytical Letters, vol. 34, no. 4, pp. 597-614, 2001.

[22] R. Soniassy, P. Sandra, and C. Schlett, "Water Analysis," 1995.

[23] W. Liu and H. K. Lee, "Quantitative analysis of pesticides by capillary column high performance liquid chromatography combined with solid-phase extraction," Talanta, pp. 631-639, 1998.

[24] E. D. Hagestuen and A. D. Campiglia, "New approach for screening polycyclic aromatic hydrocarbons in water samples," Talanta, vol. 49, no. 3, pp. 547-560, 1999.

[25] P. Kalac, M. Niznamska, D. Bevilaqua et al., "Concentrations of mercury, copper, cadmium and lead in fruiting bodies of edible mushrooms in the vicinity of a mercury smelter and a copper smelter," Science of The Total Environment, vol. 177, no. 1-3, pp. 251-258, 1996.

[26] R. Nusko and J. Fresenius, “Cr(III)/Cr(VI) speciation in aerosol particles by extractive separation and thermal ionization isotope dilution mass spectrometry," Fresenius' Journal of Analytical Chemistry, vol. 357, no. 8, p. 1050, 1997. 

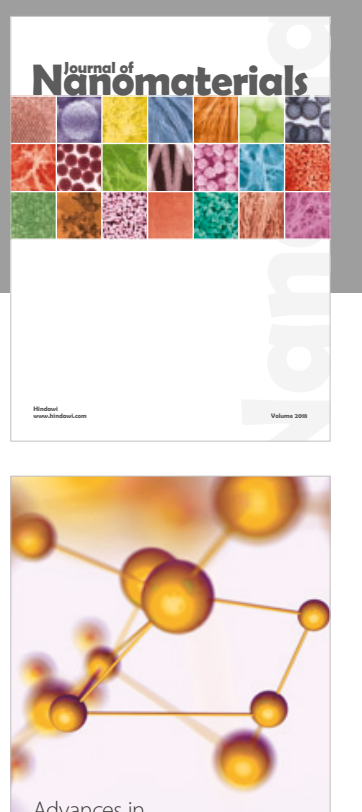

Physical Chemistry
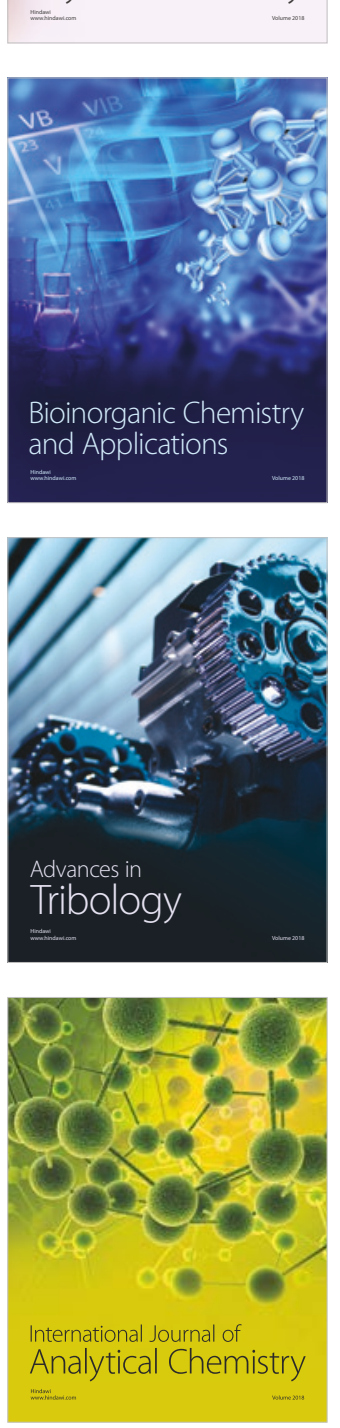

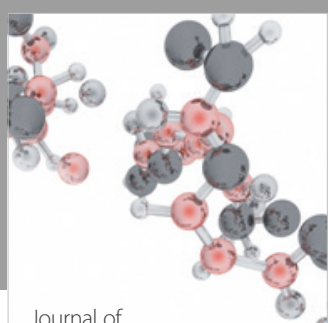

Analytical Methods

in Chemistry

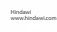

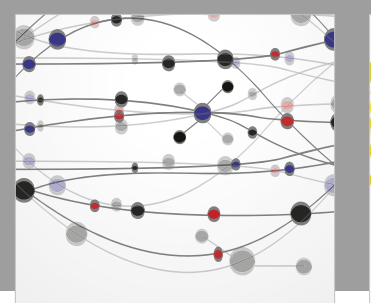

The Scientific World Journal

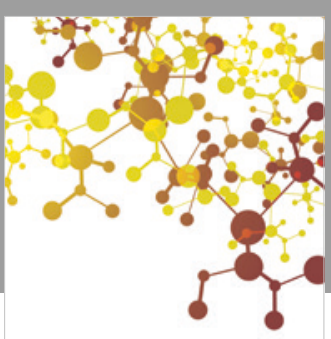

Journal of

Applied Chemistry
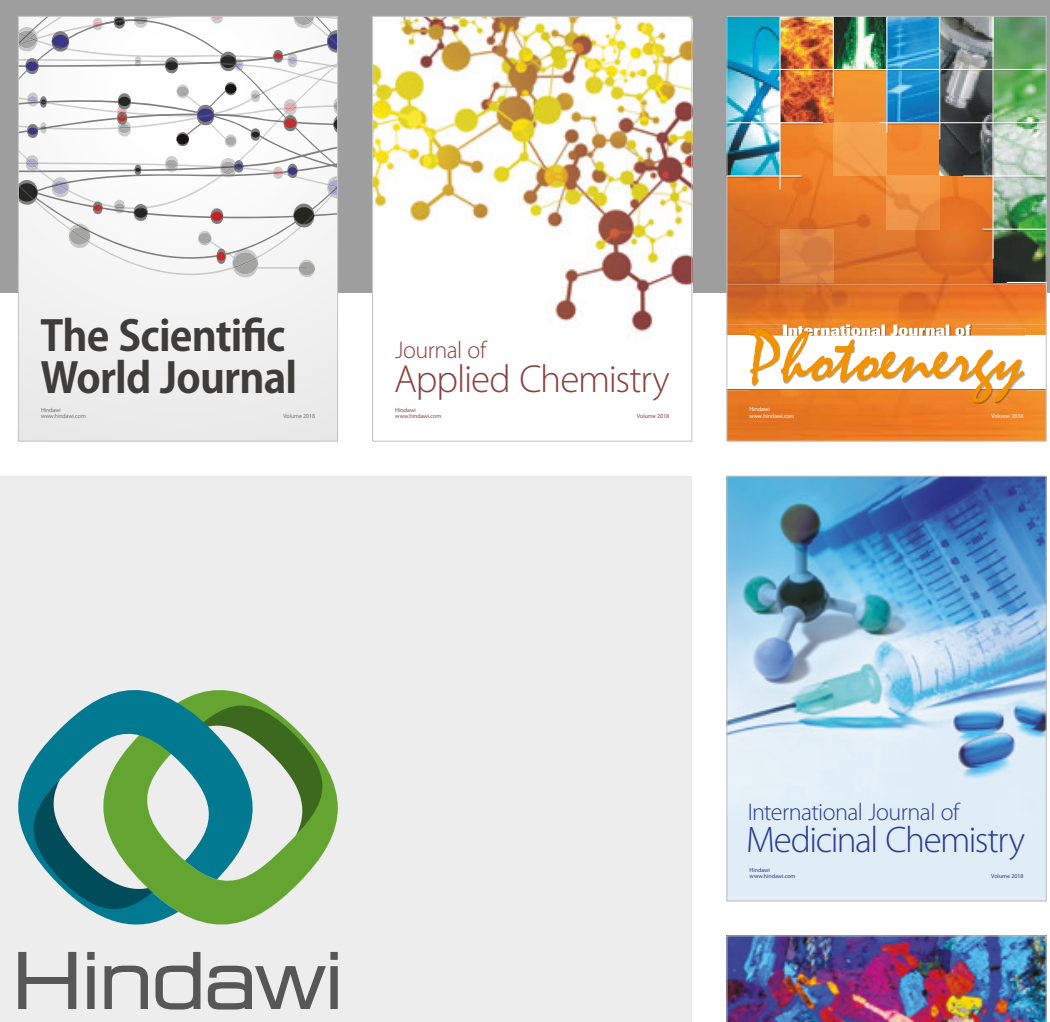

Submit your manuscripts at

www.hindawi.com
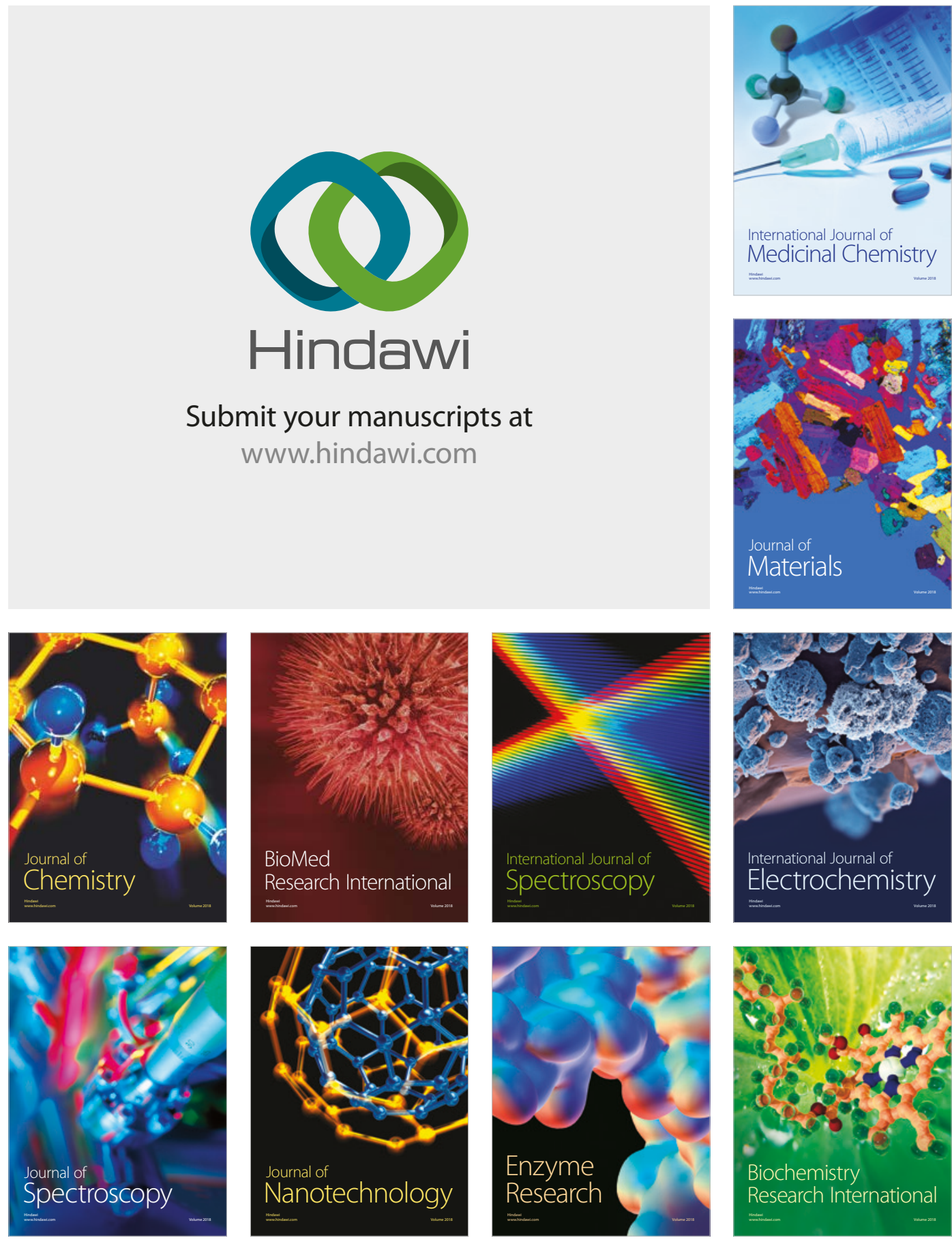
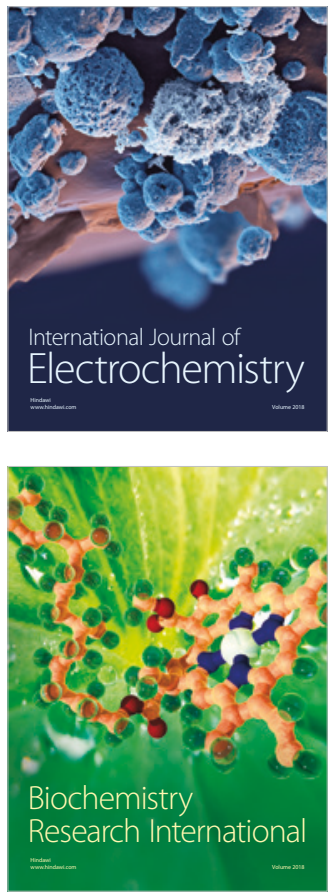